\title{
Clinico epidemiological study of measles, pertussis, diphtheria and tetanus cases in a tertiary care hospital of western Rajasthan
}

\author{
S.K. Vishnoi ${ }^{1}$, Rakesh Jora ${ }^{2, *}$, Praveen Chopra ${ }^{3}$, B.D. Gupta ${ }^{4}$ \\ ${ }^{1}$ Assistant Professor, ${ }^{2}$ Senior Professor, ${ }^{3}$ Senior Registrar, ${ }^{4}$ Ex. Professor and HOD, Dept. or Pediatrics, Dr. S.N. Medical \\ College, Jodhpur, Rajasthan, India
}

*Corresponding Author:

Email: jorarakesh@gmail.com

\begin{abstract}
Introduction: Vaccine preventable infectious diseases like measles, whooping cough, tetanus and diphtheria are very important causes of morbidity and mortality in the younger infants and children in developing countries. The present study was therefore planned to evaluate and elaborate the factors responsible for this scenario.

Materials and Methods: The current study was carried out in the Department of Pediatrics, Umaid Hospital, Dr. S.N. Medical College, Jodhpur, over a period of 12 months. During this period admitted cases of measles, whooping cough, diphtheria and tetanus were included in the present study. The diagnosis of vaccine preventable disease was made on clinical ground and supportive laboratory evidence \& complications of these diseases were also studied.

Results: The incidence of vaccine preventable diseases was $1.63 \%$ amongst hospitalized cases during the study period. Incidences of measles, pertussis, tetanus and diphtheria were $0.85 \%, 0.47 \%, 0.15 \%$ and $0.14 \%$ respectively. Measles cases $(52.40 \%)$ were highest in number amongst all vaccine preventable diseases. Pneumonia was the main respiratory complication in measles $(82.44 \%)$ and pertussis cases $(78.07 \%)$. The mortality rates of measles, pertussis \& diphtheria were $6.8 \%, 2.73 \%$ and $13.63 \%$ respectively.

Conclusion: There is still a very high incidence of vaccine preventable diseases despite multiple national programmes and ongoing stress on these and associated programmes. Reappraisal of immunization programs and strategies including effective control measures will ultimately help to eradicate the vaccine preventable diseases.
\end{abstract}

Keywords: Infectious diseases, Preventable disease, Immunization and vaccination.

\section{Introduction}

Vaccine preventable infectious diseases like measles, whooping cough, tetanus and diphtheria are very important causes of morbidity and mortality in the younger infants and children in developing countries. In India, particularly because of total population, the contribution to mortality is much more. ${ }^{1,2}$ Measles and pertussis can precipitate malnutrition, flare up tuberculosis and are continuous menace to health of children. Case fatality rate of measles, pertussis, tetanus and diphtheria were $2.48 \%, 0.5 \%, 40 \%$ and $10 \%$ respectively. These data tells us about the burden of vaccine preventable diseases over the world. ${ }^{1}$

As is evident from the aforementioned illustrations that despite best possible efforts to reduce the incidence of vaccine preventable diseases, there have been an increase in their incidence. ${ }^{3}$ Moreover, according to WHO, reported percentage of children in India, who received vaccination against BCG, DPT-3 and Measles in 1990 was $99 \%, 99 \%$ and $91 \%$ respectively, but in 2001 it was $73 \%, 64 \%$ and $56 \%$ only. Unexpectedly, despite better accessibility and stress on immunization, there is a marked decrease in the rate of vaccination in India. $^{4}$

Immunization is one of the most cost-effective health interventions known to mankind. Immunization is the single most successful child survival strategy the world over. Immunization also reduces morbidity to great extent. ${ }^{5}$ Unfortunately, in our country the routine immunization coverage rates have slipped down over last few years. This is a matter of great concern to all of us. There is an urgent need to reinforce quality immunization services. Recent coverage evaluation surveys and studies conducted in India have reported that the percentage of fully immunized infants is only $38 \%$. In light of the scenario described in the aforementioned account it is very clear that the incidence of vaccine preventable diseases in India has been increasing in the recent years and the prevalence of immunization against these diseases has decreased due to multiple technical and epidemiologic factors.

The present study was therefore planned to study the clinical features and complications of measles, whooping cough, tetanus and diphtheria and their relation with age, sex, nutritional status and socioeconomic status.

\section{Materials and Methods}

The study was carried out in the Department of Pediatrics, Umaid Hospital, Dr. S.N. Medical College, Jodhpur, over a period of one year. A total of 250 admitted cases of measles, whooping cough, diphtheria and tetanus were included in the present study.

A special predesigned proforma was used to record the present, past and family history, development assessment and vaccination status with details of general physical \& systemic examination. Information was collected either from mother or father or any other 
close relative attending the child at the hospital. Apart from the history, a detailed general and systemic examination of each child was carried out and was recorded in the proforma, specially designed for the study.

We also took details of patients regarding age, sex, religion, rural or urban residence, time of admission in the predesigned proforma. In past history we took the history particularly for any vaccine preventable disease occurring before. Similarly, we also asked the history of any vaccine preventable disease in other siblings or neighborhood. Anthropometry was recorded particularly weight of child and nutritional status of the child was calculated according to the IAP classification.

The complete general physical examination was done including eyes, neck, skin, edema feed, lymphadenopathy etc. We also examined all the system and complications affecting these systems in detail.

The diagnosis of vaccine preventable disease was made on clinical ground and supportive laboratory evidence. Complications due to vaccine preventable diseases were also studied in detail. The statistical analysis was performed by Chi-square test and Z-test to find out the significance of difference

\section{Results}

Total 250 cases of vaccine preventable diseases were enrolled in this study. The complete epidemiological and clinical profiles of these patients were studied. The overall incidence of vaccine preventable diseases was $1.63 \%$. The incidences of measles, pertussis, tetanus and diphtheria were $0.85 \%$, $0.47 \%, 0.15 \%$ and $0.14 \%$ respectively. Measles cases $(52.40 \%)$ were highest in number amongst all vaccine preventable diseases (Table 1). Measles cases were more common in first two quarters, i.e. January to March (52.67\%) and April to June (35.11\%), and the observed difference with other quarters was statistically significant ( $\mathrm{p}<0.001)$ while pertussis was more common in first quarter, i.e. January to March $(41.09 \%)$ followed by $30.13 \%$ in fourth quarter (October to December) and difference was statistically insignificant ( $p>0.05$ ). Tetanus cases were almost equidistributed throughout the year. The diphtheria was most common in fourth quarter, i.e. October to December (63.63\%). The observed difference was statistically significant with others quarters $(\mathrm{p}<0.001)$ (Table 2).

Measles, pertussis and diphtheria cases were more common in age group 1 to 5 years $(63.35 \%, 50.68 \%$ and $59.09 \%$ ) while tetanus cases were relatively common in age group more than 5 years $(45.83 \%)$. Majority of patients with vaccine preventable diseases were males $(65.20 \%)$ as compared to females $(34.80 \%)$. Majority of patients were from rural as compared to urban areas $(32.80 \%)$. Malnutrition was present in $58.02 \%$ of measles, $53.43 \%$ of pertussis, $62.51 \%$ of tetanus and $72.73 \%$ of diphtheria cases (Table 3).

Main complications of Measles and Pertussis were respiratory (pneumonia), gastrointestinal (diarrhea, refusal to feed) and ophthalmic (keratomalacia, xerosis and subconjuctival hemorrhage) while CNS (encephalopathy \& palatal palsy) and CVS (Myocarditis) complications mainly seen with Diphtheria.

Higher mortality rate was found in tetanus [25\%]. The mortality rates of measles, pertussis \& diphtheria were $6.8 \%, 2.73 \%$ and $13.63 \%$ respectively. The main cause of mortality in measles was bronchopneumonia [3.05\%]. Total deaths due to vaccine preventable diseases were $20(8.0 \%)$. The maximum mortality $(70 \%)$ among vaccine preventable diseases was observed in age group 1-5 years \& nearly two third expired cases of the vaccine preventable diseases had protein energy malnutrition (Table 4).

Table 1: Incidence of vaccine preventable diseases among hospitalized patients

\begin{tabular}{|l|c|c|c|}
\hline & \multirow{2}{*}{ No. of Cases } & \multicolumn{2}{|c|}{ Percentage (\%) } \\
\cline { 3 - 4 } & & $\mathbf{n = 1 5 2 7 1}$ & $\mathbf{n = 2 5 0}$ \\
\hline 1. Total Hospitalized cases & 15271 & $100 \%$ & - \\
\hline 2. Vaccine preventable diseases & 250 & 1.63 & $100 \%$ \\
\hline 3. Measles & 131 & 0.85 & 52.40 \\
\hline 4. Pertussis & 73 & 0.47 & 29.20 \\
\hline 5. Tetanus & 24 & 0.15 & 9.60 \\
\hline 6. Diphtheria & 22 & 0.14 & 8.80 \\
\hline 7. Polio & - & - & - \\
\hline
\end{tabular}

Table 2: Quarter wise distribution of vaccine preventable diseases

\begin{tabular}{|c|c|c|c|c|c|c|c|c|c|}
\hline \multirow[b]{2}{*}{ Quarters } & \multicolumn{2}{|c|}{ Measles } & \multicolumn{2}{|c|}{ Pertussis } & \multicolumn{2}{|c|}{ Tetanus } & \multicolumn{2}{|c|}{ Diphtheria } & \multirow{2}{*}{$\begin{array}{l}\text { No. of admitted } \\
\text { cases }\end{array}$} \\
\hline & No. & $\%$ & No. & $\%$ & No. & $\%$ & No. & $\%$ & \\
\hline Jan-Mar. $07\left(\mathrm{Q}_{1}\right)$ & 69 & 52.67 & 30 & 41.09 & 5 & 20.83 & 5 & 22.72 & 3244 \\
\hline Apr-June $07\left(\mathrm{Q}_{2}\right)$ & 46 & 35.11 & 17 & 23.28 & 8 & 33.33 & - & - & 3539 \\
\hline July-Sep 07 (Q3) & 1 & 0.76 & 4 & 5.47 & 4 & 16.66 & 3 & 13.63 & 3928 \\
\hline Oct-Dec06 $\left(\mathrm{Q}_{4}\right)$ & 15 & 11.40 & 22 & 30.13 & 7 & 29.16 & 14 & 63.63 & 4560 \\
\hline Total & 131 & 100 & 73 & 100 & 24 & 100 & 22 & 100 & 15271 \\
\hline
\end{tabular}

IP International Journal of Medical Paediatrics and Oncology, April-June, 2018:4(2):63-66 
Table 3: Nutritional status of vaccine preventable diseases patients

\begin{tabular}{|l|c|c|c|c|c|c|c|c|c|c|}
\hline \multirow{2}{*}{$\begin{array}{c}\text { Nutritional } \\
\text { Status }\end{array}$} & \multicolumn{2}{|c|}{ Measles } & \multicolumn{2}{|c|}{ Pertussis } & \multicolumn{2}{c|}{ Tetanus } & \multicolumn{2}{c|}{ Diphtheria } & \multirow{2}{*}{ No. } & \multirow{2}{*}{ (n=250) } \\
\cline { 2 - 12 } & $\mathbf{N o .}$ & $\mathbf{\%}$ & $\mathbf{N o .}$ & $\mathbf{\%}$ & $\mathbf{N o}$ & $\mathbf{\%}$ & $\mathbf{N o .}$ & $\mathbf{\%}$ & & \\
\hline Grade I & 26 & 19.84 & 18 & 24.65 & 5 & 20.83 & 8 & 36.36 & 57 & 22.80 \\
\hline Grade II & 25 & 19.08 & 13 & 17.80 & 4 & 16.66 & 6 & 27.27 & 48 & 19.20 \\
\hline Grade III & 20 & 15.26 & 7 & 9.58 & 4 & 16.66 & 2 & 9.09 & 33 & 13.20 \\
\hline Grade IV & 5 & 3.81 & 1 & 1.36 & 2 & 8.33 & - & - & 8 & 3.20 \\
\hline $\begin{array}{l}\text { Normal } \\
\text { Weight }\end{array}$ & 55 & 41.98 & 34 & 46.57 & 9 & 37.50 & 6 & 27.27 & 104 & 41.60 \\
\hline \multicolumn{1}{|c|}{ Total } & $\mathbf{1 3 1}$ & $\mathbf{1 0 0}$ & $\mathbf{7 3}$ & $\mathbf{1 0 0}$ & $\mathbf{2 4}$ & $\mathbf{1 0 0}$ & $\mathbf{2 2}$ & $\mathbf{1 0 0}$ & $\mathbf{2 5 0}$ & $\mathbf{1 0 0}$ \\
\hline
\end{tabular}

Table 4: Impact of nutrition status over the mortality of vaccine preventable diseases

\begin{tabular}{|c|c|c|c|c|c|c|c|c|c|c|c|c|}
\hline \multirow{3}{*}{$\begin{array}{l}\text { Nutritional } \\
\text { Status }\end{array}$} & \multicolumn{3}{|c|}{ Measles } & \multicolumn{3}{|c|}{ Pertussis } & \multicolumn{3}{|c|}{ Tetanus } & \multicolumn{3}{|c|}{ Diphtheria } \\
\hline & \multicolumn{2}{|c|}{ No. } & \multirow[t]{2}{*}{$\%$} & \multicolumn{2}{|c|}{ No. } & \multirow[t]{2}{*}{$\%$} & \multicolumn{2}{|c|}{ No. } & \multirow[t]{2}{*}{$\%$} & \multicolumn{2}{|c|}{ No. } & \multirow[t]{2}{*}{$\%$} \\
\hline & D. & C. & & D. & C. & & D. & C. & & D. & C. & \\
\hline Grade I & 1 & 26 & 3.84 & 1 & 18 & 5.55 & 2 & 5 & 40.0 & - & 8 & - \\
\hline Grade II & 2 & 25 & 8.00 & 1 & 13 & 7.69 & 2 & 4 & 50.0 & 1 & 6 & 16.66 \\
\hline Grade III & 2 & 20 & 10.00 & - & 7 & - & - & 4 & - & 1 & 2 & 50.00 \\
\hline Grade IV & - & 5 & - & - & 1 & - & - & 2 & - & - & - & - \\
\hline Normal Wt. & 4 & 55 & 7.27 & - & 34 & - & 2 & 9 & 22.2 & 1 & 6 & 16.66 \\
\hline Total & 9 & 131 & - & 2 & 73 & - & 6 & 24 & & 3 & 22 & - \\
\hline
\end{tabular}

\section{Discussion}

Vaccine preventable diseases have been one of the most important public health problem since times immemorial and their eradication is a very distant dream. The morbidity and mortality rates due to these diseases have not changed satisfactorily in our area, requiring a reappraisal and reassessment of the present clinical scenario of these diseases and vaccination coverage in our area.

In the present study, the incidence of measles amongst hospitalized patients to be $0.85 \%$. This incidence is lower as compared to the incidence reported by Desai et al ${ }^{5}$ in Surat (7.6\%) and by Satpathy and Chakraborty in Singur (4\%). ${ }^{6}$ The incidence of various vaccines preventable diseases observed in our study may be different from other studies may an underreporting of the cases due to technical reasons and community based surveys and studies are the truly reflective of the incidence and prevalence of these studies.

Nelson. ${ }^{7}$ Rashmi et $\mathrm{al}^{8}$ and, Sekhari and Nair ${ }^{9}$ have also reported that the maximum incidence of measles occurs in months of February to April. It is a known fact that measles is more common in winter season because of overcrowding and favorable transmission of viral infections during winter and spring season. Singh and Sharma ${ }^{10}$ in their study reported that epidemics of pertussis may occur in any season with increased frequency in winter season. Vaccine preventable diseases were more common in infants and pre-school age children in our study.

$82 \%$ cases of vaccine preventable diseases occurred in age group 1 month to 5 years. In general, there is always a male biasness in seeking health care facilities and females are deprived throughout the country from basic health care facilities and other social aspects. Therefore, the male preponderance amongst admitted patients due to various vaccine preventable diseases does not come as a surprise.

We found that the cases of measles, pertussis, tetanus and diphtheria admitted with protein energy malnutrition were $58.02 \%, 53.43 \%, 62.5 \%$ and $72.73 \%$ respectively. Bharti and Bharti ${ }^{11}$ in their study observed that $92 \%$ of children were malnourished in their study. Krishanmurthy and Ananthram ${ }^{12}$ reported $80 \%$ of children with malnutrition while Parikh ${ }^{13}$ found that $76 \%$ of measles cases were having malnutrition and out of them $73.68 \%$ were having PEM grade II and III. Malnutrition is the main factor contributing to morbidity and mortality because of vaccine preventable disease stend to be very severe in the malnourished child.

The mortality rate of measles in present study was $6.8 \%$. According to $\mathrm{WHO}$, the mortality rate due to measles ranges from $2-15 \%$. On the contrary, Singh et $\mathrm{al}^{10}$ reported mortality rate of $1-2 \%$ only and Bharti and Bharti $^{11}$ reported mortality rate of $3.57 \%$. Thus, the mortality rate of measles observed in our study was similar to that given by WHO. In our study, only two cases of pertussis expired, with a mortality rate of $2.73 \%$. The causes of mortality in pertussis were bronchopneumonia (1.36\%) and encephalopathy $(1.36 \%)$. The mortality rate of tetanus was $25 \%$, two cases expired due to neonatal tetanus $(8.33 \%)$ and four older children expired due to uncontrolled convulsions $(16.67 \%)$ while that of Diphtheria was $13.63 \%$ with myocarditis being the main cause of mortality $(9.09 \%)$. In our study we could not find any specific cause for the age related mortality statistics. However, younger 
age group patients may have relatively severe complications contributing to increased mortality.

As PEM grade increases percentage of mortality also increases. Severe malnutrition in children results in suboptimal immune response leading to higher morbidity and mortality in vaccine preventable diseases.

\section{Conclusion}

In fact, looking to the increasing trend of vaccine preventable diseases, it becomes paramount to review strategies to improve routine immunization and its subsequent implementation in the problem areas. Reappraisal of immunization programs and strategies including effective control measures will ultimately help to eradicate these diseases.

Conflict of Interest: All authors contributed to study design and drafting of manuscript $\&$ there is no conflict of interest

\section{References}

1. K. Park. Epidemiology of communicable diseases, Textbook of preventive and social medicine. Jabalpur: Banarsidas Bhanots 2007;19:126-264.

2. Kliegman, Behrman, Jenson, Stanton et al. Nelson Text book of Pediatrics. Sunders 2008;18:1153-1336.

3. WHO Vaccine-preventable diseases: monitoring system 2006 global summary- Country Profile India: 2006; 1 to 2 .

4. CIRO A de Quadros. Bull WHO 2004;82:134-138.

5. Desai VK, Kapadia SJ, Kumar P, Nirupam Siddharth. A study of measles incidence and vaccination coverage in the slums of Surat City. Indian J Community Med (accepted for publication), 2002.

6. Satpathy SK, Chakraborty AK. Epidemiological study of measles in Singur, West Bengal. J Comm Dis 1990; 22(1):23-26.

7. Kliegman, Behrman, Jenson, Stanton et al. Nelson Text book of Pediatrics. $18^{\text {th }}$ edition. Sunders: 2008;11531336.

8. Rashmi Arun, Guha D.K. and Khanduja P.C. Post measles pulmonary complications in children. Ind. Paed., 8:834.

9. Sekhari Rita and Vasanthbahi Nair. Post-measles complications, Paed. Clin. of India; 9:83;1974.

10. Singh J, Sharma RS, Verghese T. Measles mortality in India: a review of community based studies. J Comm Dis 1994;26:203-214.

11. Bharti and Bharti et al. Measles in a Hilly Hamlet of Northern India. Indian Journal of Pediatrics, Volume 69; December, 2002.

12. Krishanmurthy and Ananthram Measles, a dangerous disease. A study of 1000 cases in Madurai. Ind. Paed., 11:267;1974.

13. Parikh V.S. Post measles complications. A study of 100 cases. Dissertation (Gujarat University) for the degree of M.D. (Paed.), 1981. 